\title{
Tracking antioxidant properties and color changes in low-sugar bilberry jam as effect of processing, storage and pectin concentration
}

\author{
Mariana-Atena Poiana*, Ersilia Alexa and Constantin Mateescu
}

\begin{abstract}
Background: Recently, an increased interest in the identification of valuable possibilities for preserving the antioxidant properties of products obtained by thermal processing of fruits rich in bioactive compounds can be noticed. In this regard, an extensive analysis is necessary in terms of thermal processed products behavior in relation to various factors. The purpose of the present study was to assess the effect which processing and storage at $20^{\circ} \mathrm{C}$ has on the antioxidant properties and color quality of low-sugar bilberry jam with different low-methoxyl pectin (LMP) concentrations.

Results: For all measured parameters, it should be noted that thermal processing induced significant alterations reported to the values registered for fresh fruit. Most important losses due to thermal processing were recorded for total monomeric anthocyanins (TMA) (81-84\%), followed by L-ascorbic acid (L-AsAc) content (53-58\%), total phenolics (TP) content (42-51\%) and FRAP (ferric reducing antioxidant power) values (36-47\%). Moreover, depreciation of the investigated compounds occurred during storage at $20^{\circ} \mathrm{C}$. Jam storage for 7 months resulted in severe losses in TMA content in the range 58-72\% from the value recorded one day after processing. This coincided with marked increases in polymeric color percent of these products after 7 months of storage. Also, bilberry jam storage for 7 months resulted in a decrease in L-AsAc content of 40-53\% from the value recorded one day after processing, 41-57\% in TP content and 33-46\% from the value recorded one day after processing for FRAP values. By decreasing of LMP concentration in the jam recipe from 1 to $0.3 \%$ there has been an increase in losses of investigated compounds.
\end{abstract}

Conclusion: Overall, the results indicated that bilberry jams can also represent a good source of antioxidant compounds, although compared to the fruit, important losses seem to occur. Practical application of this work is that this kind of information will be very useful in optimizing the jam processing technology and storage conditions, in order to improve the quality of these products.

Keywords: bilberry jam, FRAP, color quality, total phenolic, monomeric anthocyanins, polymeric color

\section{Background}

The significance of fruit phenolics as dietary antioxidants has recently been suggested by several research groups. Compared to other fruits, a high antioxidant capacity has been reported for bilberries. These fruits are known to contain a high level of antioxidant compounds [1-3]. Their antioxidant capacity has been attributed to their

\footnotetext{
* Correspondence: atenapoiana@yahoo.com
Banat's University of Agricultural Sciences and Veterinary Medicine, Faculty of * Correspondence: atenapoiana@yahoo.com
Banat's University of Agricultural Sciences and Veterinary Medicine, Faculty of Food Processing Technology, Calea Aradului 119, RO 300645, Timisoara, Romania
}

high concentration of phenolics, particularly anthocyanins $[4,5]$. The antioxidant capacity is most significantly correlated with the contents of total phenolics and anthocyanins, while L-ascorbic acid makes a small contribution to the total antioxidant capacity [6,7]. Bilberries have a complex mixture of anthocyanins which may fortify blood vessel walls, induced increase in flexibility of the capillaries, improve blood flow and maintain good circulation [8-10]. Polyphenolic compounds including anthocyanins and proanthocyanidins are not completely stable. After harvest these compounds can change during food 
processing and storage, which may reduce related biological activity [11-13]. The researches on high antioxidant capacity of bilberries have sparked considerable interest among consumers who want to know how bilberries can contribute to the nutritional quality of their diet $[6,14]$.

Wild bilberry is very important natural resource of Romania. Although most bilberries are marketed fresh, substantial quantities are processed into shelf-life products, available to consumers all year round. The most popular product is jam. Taking into account the nutritional recommendations and the health benefits, many people prefer the consumption of low-sugar jams. Lowsugar jams were originally developed for diabetics and people with specific health problems. One question that arises is whether the high quality low-sugar jams could represent a good source of bioactive compounds as fresh fruit does. Currently there is a continuing concern in order to improve the retention of bioactive compounds in products obtained by thermal processing of fruits rich in anthocyanins $[15,16]$. Besides their nutritional properties, the color of bilberry jam is an important factor influencing consumer acceptability, thus minimizing anthocyanins losses during processing and storage is in primary concern $[4,17]$. Anthocyanins content has a critical role in the color quality of many fresh and processed fruits. During processing and storage, degradation and polymerization usually lead to its discoloration $[8,18]$. Temperature, oxygen, $\mathrm{pH}$, light illumination, water activity, presence of saccharides and their degradation products and activities of various enzymes are considered to be important factors influencing anthocyanins stability and bioactive compounds content $[4,19,20]$. Generally, temperature and duration of boiling and pasteurization, jam recipe (sugar, citric acid content and pectin concentration), degree of fruit ripeness as well as storage conditions of products are the most important factors determining the quality of blueberry jam [17,21-23]. Also, processing methods varying in the number of processing steps and techniques, heating temperature, processing period and storage conditions can significantly affect the phenolics content, L-ascorbic acid, antioxidant capacity and color quality of fruit products $[24,25]$. The antioxidant activity in the course of processing may also be affected by the loss of watersoluble antioxidants, such as phenolics, or interactions with non-phenolics compounds [26,27]. However, there are also reports demonstrating non-phenolic food components to stabilize anthocyanins. Some hydrocolloids, especially pectin, have recently been shown to enhance color stability in a model gel system, where as other hydrocolloids had no or even adverse effects [28]. The effect of the pectin concentration on the jam color has not been extensively studied. Although it has been suggested that pectin has a role in the color degradation of the jam products, this effect is not yet accurately known $[29,30]$. Unfortunately, limited information is available on how processing and storage of jams with different pectin concentration influence the retention of bilberry antioxidant characteristics and color properties. Since high antioxidant capacity is a desirable characteristic for foods and the color is one of the most important attributes, significantly deciding over consumer preference, this study was undertaken to determine the stability of total phenolics, anthocyanins, L-ascorbic acid, antioxidant capacity and color indices in low-sugar bilberry jams with different pectin concentrations following processing and storage at $20^{\circ} \mathrm{C}$.

\section{Results and Discussion}

Chemical parameters of fresh bilberries used in this study for jam processing were reported in the Table 1. They are very important because it provides information on the magnitude of alterations due to thermal processing of fruit. Low-sugar jams with different LMP concentration were analyzed one day after processing (0) and during storage at $20^{\circ} \mathrm{C}$ (after $1,3,5$ and 7 months) for total monomeric anthocyanins, total phenolics, Lascorbic acid, color density, polymeric color (\%) and FRAP values. To provide a clear view on the changes occurred for investigated parameters as a result of different pectin concentration in the jam formulation and storage time, the results obtained in this study were processed by two-way ANOVA test. Based on information obtained through statistical processing can be pointed the significance of changes in monitored bioactive compounds and color parameter of bilberry jam as response to pectin concentration and storage period.

\section{Total anthocyanins content and color}

In jams, TMA content per $100 \mathrm{~g}$ fresh weight were much lower than in the corresponding fresh fruit. Based on the amount of fruit needed to obtain $100 \mathrm{~g}$ jam was determined the theoretical content of TMA from the bilberry jam. Since jams contained about $69 \mathrm{~g}$ of fresh fruit per $100 \mathrm{~g}$, it was to be expected that TMA content would be approximately $69 \%$ from the value registered

Table 1 Chemical characteristics of fresh bilberries used in this study

\begin{tabular}{|c|c|}
\hline Component (Units) & Values \\
\hline Total phenolics (mg gallic acid $100^{-1} \mathrm{~g}$ fresh bilberries) & $683.88 \pm 25.52$ \\
\hline Total anthocyanins content ( $\mathrm{mg} \cdot 100^{-1} \mathrm{~g}$ fresh bilberries) & $238.51 \pm 18.73$ \\
\hline Antioxidant activity (mM Fe ${ }^{2+\cdot} 100^{-1} \mathrm{~g}$ fresh bilberries) & $5.53 \pm 0.38$ \\
\hline L-ascorbic acid (mg·100-1 $\mathrm{g}$ fresh bilberries) & $17.09 \pm 1.22$ \\
\hline Color density & $12.31 \pm 0.94$ \\
\hline Polymeric color & $0.38 \pm 0.025$ \\
\hline Percent polymeric color (\%) & $3.09 \pm 0.27$ \\
\hline
\end{tabular}


for fresh fruit. The difference between the theoretical content of TMA and the real content of TMA recorded for bilberry jam was caused by thermal processing. It can be seen the massive decrease of TMA content due to thermal processing (Tables 1 and 2). Thus, jam preparation caused a decrease of total anthocyanins content by $81-84 \%$ of the value registered for the corresponding fresh fruit. This result is in agreement of other studies of bilberries, where the reduction of total anthocyanins after jam processing was 85\% [16]. Pinto et al. [31] showed that anthocyanins are very sensitive to temperature, and a combined time/temperature process can greatly reduce the level of pigments in the final product. Anthocyanins losses are probably due to complexation with co-occurring compounds during jam processing. Losses of anthocyanins and/or formation of brown compounds in jam during storage have been attributed to many factors such as $\mathrm{pH}$, phenolic compounds, sugars and sugar degradation products, oxygen, ascorbic acid, fruit maturity and thawing time. Other factors may have a significant role in the expression of color in fruit jams by copigmentation or some other physico-chemical processes $[29,32,33]$. The losses of monomeric anthocyanins were most likely due to the formation of anthocyanins polymers or condensation reactions among anthocyanins and procyanidins during the jam processing steps and storage period of these $[25,34]$.

The changes of TMA content in bilberry jam as results of pectin concentrations and storage time are shown in Table 2. In respect of the TMA content in jam directly after production, it can be seen that the highest content of monomeric anthocyanins was recorded in jam with 1\% LMP (low-methoxyl pectin). With increasing of LMP concentration in jam increases the amount of retained anthocyanins. By increasing of LMP concentration in the formulation from 0.3 to $1 \%$ there was an increase in TMA content of $13 \%$. Since pectin is polyuronic acid, their color stabilizing effect may be based on electrostatic interactions between the anthocyanin flavilium cation and the dissociated carboxylic groups of the pectin. Due to this association, anthocyanins may be prevented from water attack, which leads in turn to color stabilization [35]. Prolonged storage may affect hydrolysis of compounds and lead to gradual reduction in anthocyanins content, as observed in our study. The level of monomeric anthocyanins decreases gradually during storage, losing about $23-31 \%$ from the value recorded one day after processing at the end of 3 months of storage (Figure 1a). Jam storage at room temperature for 7 months caused further reduction of TMA content by $58-72 \%$ from the value recorded one day after processing. These findings of more extensive degradation of monomeric anthocyanins during storage at $20^{\circ} \mathrm{C}$ for jam with low dose of pectin are consistent with previously reported data [29]. Nevertheless, it may be assumed that the oxidative reaction proceeds in jams during storage, even if the jams in our experiment were hot-packed into glass jars. A strong reduction of anthocyanins during storage was also reported for pigments of red raspberry jams [21]. Polyphenoloxidase, peroxidase, and glycosidase enzymes can have a devastating effect on anthocyanins. Light exposure will promote pigment destruction while reduced water activity will enhance stability $[4,19]$.

From the statistical test using two-way ANOVA it could be concluded that the stability of monomeric anthocyanins and the extent of their degradation was markedly affected by storage period and to a lesser extent by the LMP concentration $(\mathrm{P}<0.05)$. It is evidently from the Table 2 that storage time has more influence on total monomeric anthocyanins content than the level of LMP. At any level of LMP the decrease of monomeric anthocyanins content with the storage time has statistically significance at $\mathrm{P}<0.05$. In contrast, for the fresh jam the decrease of monomeric anthocyanins content with LMP content at $\mathrm{P}<0.05$ has not any statistical significance.

The effect of processing, LMP concentration and storage for 7 months at $20^{\circ} \mathrm{C}$ on bilberry jam color was quantified by measuring the following color parameters: color density, polymeric color and polymeric color (\%). Polymeric color (\%) value is the ratio between polymeric color and color density being used to determine the percentage of the color that is contributed by polymerized

Table 2 Alterations of total monomeric anthocyanins content in jam as effect of LMP concentration and storage time

\begin{tabular}{|c|c|c|c|c|c|}
\hline \multirow[t]{3}{*}{ Samples } & \multicolumn{5}{|c|}{ Total anthocyanins content $\left(\mathrm{mg} \cdot 100^{-1} \mathrm{~g}\right.$ jam $)$} \\
\hline & \multicolumn{5}{|c|}{ storage time (months) } \\
\hline & 0 & 1 & 3 & 5 & 7 \\
\hline $1.0 \% \mathrm{LMP}$ & $30.74 \pm 1.86^{a_{1} A}$ & $27.63 \pm 1.54^{\mathrm{ab}, \mathrm{A}}$ & $23.56 \pm 1.93^{\mathrm{b}, \mathrm{A}}$ & $18.45 \pm 1.64^{\mathrm{C}, \mathrm{A}}$ & $13.04 \pm 0.97^{\mathrm{d}, \mathrm{A}}$ \\
\hline $0.7 \%$ LMP & $30.01 \pm 1.80^{\mathrm{a}, \mathrm{A}}$ & $24.77 \pm 1.86^{\mathrm{b}, \mathrm{A}}$ & $21.60 \pm 1.65^{\mathrm{b}, \mathrm{A}}$ & $16.68 \pm 1.22^{c, A}$ & $10.46 \pm 0.91^{\mathrm{d}, \mathrm{B}}$ \\
\hline $0.5 \%$ LMP & $28.12 \pm 1.81^{\mathrm{a}, \mathrm{A}}$ & $22.75 \pm 1.75^{\mathrm{b}, ~ A B}$ & $19.80 \pm 1.61^{\mathrm{b}, \mathrm{A}}$ & $15.37 \pm 1.13^{\mathrm{c}, \mathrm{A}}$ & $9.26 \pm 0.75^{\mathrm{d}, \mathrm{BC}}$ \\
\hline $0.3 \%$ LMP & $26.63 \pm 2.06^{\mathrm{a}, \mathrm{A}}$ & $20.95 \pm 1.50^{\mathrm{b},} \mathrm{AB}$ & $18.25 \pm 1.45^{\mathrm{b}, \mathrm{AB}}$ & $13.74 \pm 1.27^{c, A B}$ & $7.42 \pm 0.58^{\mathrm{d}, c}$ \\
\hline
\end{tabular}

Means in a row (a-d across storage time) followed by the same letter are not significantly different $(P<0.05)$. Means in a column $(A-C$ across $L M P$ concentration) followed by the same letter are not significantly different $(P<0.05)$. 


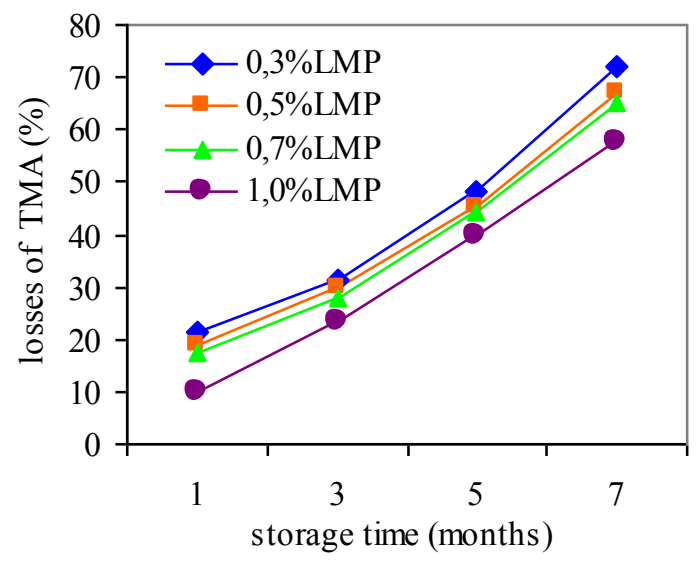

a

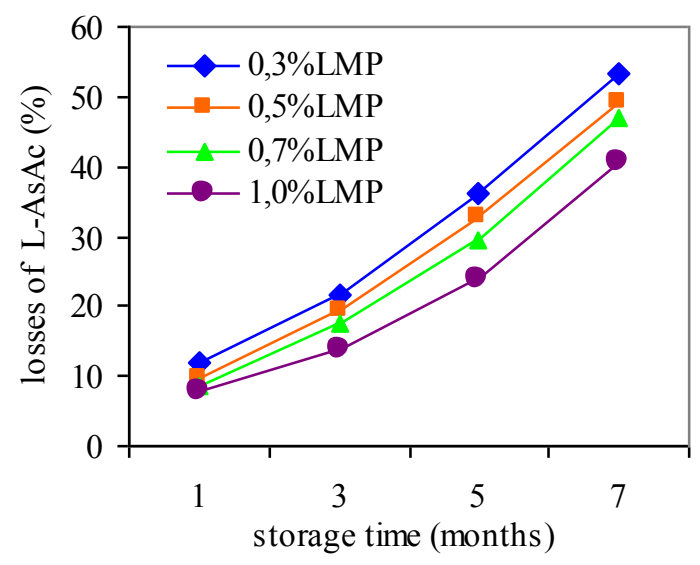

c

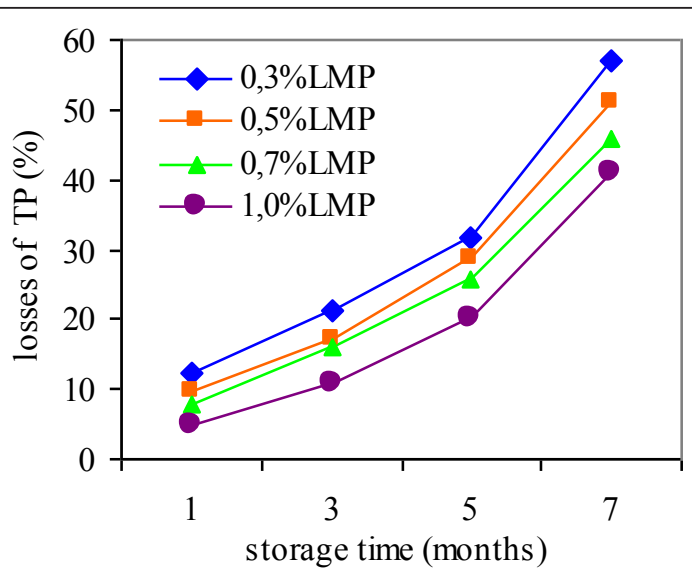

b

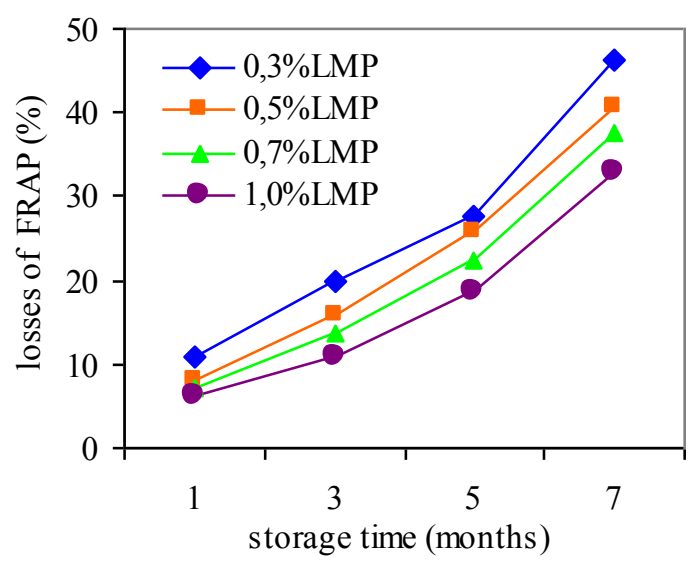

d

Figure 1 The losses of measured parameters ( $a-T M A ; b-T P ; c-L-A s A c ; d-F R A P$ ) as a result of jam storage at $20^{\circ} \mathrm{C}$ relative to the value registered one day after processing.

material [36]. Changes in the color parameters as response of LMP concentration and storage period relative to fruit jam after a day of processing were presented in the Table 3 . The polymeric color percent increased from $3.09 \%$ in fresh fruit to $9.98-13.78 \%$ in jam, depending on LMP level, indicating that anthocyanin polymers were formed in response to processing. Increasing of polymeric color values were consistent with losses of TMA content due to processing and corroborates previous studies $[18,21,25,26]$, that reported increased polymeric values in response to thermal processing of different berries. In addition to the formation of polymeric pigments, losses of anthocyanins incurred during processing may be associated with enzymatic and thermal degradation. Exposure of the berries to elevated temperatures during jam production and pasteurization most likely contributed to losses as well, because anthocyanins degradation is time and temperature dependent $[25,36]$. It has been demonstrated that the concentration of polymeric pigments increases with storage period, and this has an important influence on the color stability of juices and red wines $[4,19,34]$. It is remarkable that the rate of color density loss is much slower than the rate of anthocyanins degradation. Even for major losses recorded for TMA only minor changes were found for color density of these products stored at $20^{\circ} \mathrm{C}$, proving the stability of the jam color during the longterm storage. This can be explained by the fact that the color assigned of polymeric anthocyanins formed during storage, that are the source of "stable color" [18,19], likely compensated for the loss of color due to significant degradation of TMA during jam storage.

The effect of pectin level on jam color is still not accurately known. Pectin acts differently on the variety of anthocyanins that exist in berries. In some cases, pectin acts as a co-pigment, thus increasing the color $[32,33]$. It can be seen that decreasing of LMP concentration from 1 to $0.3 \%$ resulted in an increase of $4 \%$ in 
polymeric color percent recorded after one day of jam processing. After 7 months of storage the same reduction of LMP concentration determined an increase of approx. $11 \%$ in polymeric color percent. For jams with the same dose of pectin, the polymeric color percent increased progressively with extended of storage period. At the end of storage period, the highest value of polymeric color percent (28-33.5\%) were obtained for samples with the lowest LMP doses (0.3-0.5\%). In our study, during jam storage, a tendency towards slowing of increase in polymeric color values with increasing of LMP concentration in the jam recipe was remarked. This is due to associantions formed as a results of interactions between anthocyanins flavilium cation and the dissociated carboxilic grups of the pectin. It is likely that due to this stabilising effect, anthocyanins may be prevented of condensation reactions among anthocyanins and procyanidins. The crosslink formed between anthocyanins and procyanidins is no more stable than those existing between anthocyanins and pectin.

From the statistical test using two-way ANOVA it may be noted that the LMP dose did not exert a major impact on the polymeric color percent recorded for a jam immediately after processing, but with increasing of storage time its effect became statistically significant ( $\mathrm{P}$ $<0.05)$. Color density decreased as effect of thermal processing of bilberry from 12.31 in fresh berries to 11.25-11.82 in jam, in relation to LMP level. It can be observed that the color density of jam undergoes minor changes by increasing the LMP dose from 0.3 to $1 \%$. Following the analysis of color after one day of jam processing was a slight increase in color density value of approx. $5 \%$ by increasing the LMP level from 0.3 to $1 \%$. This increase becomes $7.5 \%$ after 7 of months of jam storage at $20^{\circ} \mathrm{C}$. This parameter decreased slightly with increasing of storage time, so that, even after 7 months there were no significant changes in the color density. Thus, on the basis of statistical test using two-way ANOVA it could be concluded that the LMP concentration and storage time induced non-significant changes in color density (Table 3), demonstrating that this parameter was not only stable in response to processing but were also stable during long-term storage.

\section{Total phenolics content}

The impact of thermal processing on the TP content was appreciated in the basis of the values that where recorded in fruit and jam. Also, the effect of LMP concentration and storage period on the TP content in bilberry jam was examined and the results are presented in Table 4. It can be observed that, by thermal processing of wild bilberries have occurred major alterations of TP content. Previous studies reported losses in TP content as effect of thermal processing of various berries, but the degree of alteration of total phenolics had different magnitudes $[13,16,20]$.

A significant decrease in TP contents between 42-51\% of the value registered directly after processing was observed as a result of processing. The largest loss in TP content was noticed after processing in jam with $0.3 \%$ pectin. By increasing the LMP dose from 0.3 to $1 \%$ has been an increase in TP content about 16\% for bilberries jam after a day of processing. In addition to the LMP dose used in the jam recipe it was noted that the

Table 3 Changes of jam color as effect of LMP concentration and storage time

\begin{tabular}{|c|c|c|c|c|c|}
\hline \multirow[t]{3}{*}{ Samples } & \multicolumn{5}{|c|}{ storage time (months) } \\
\hline & 0 & 1 & 3 & 5 & 7 \\
\hline & \multicolumn{5}{|c|}{ color density } \\
\hline $1.0 \%$ LMP & $11.82 \pm 0.88^{\mathrm{a}, \mathrm{A}}$ & $11.64 \pm 0.62^{a_{1} A}$ & $11.21 \pm 0.77^{a_{1}} \mathrm{~A}$ & $10.53 \pm 0.86^{\mathrm{a}, \mathrm{A}}$ & $10.07 \pm 0.77^{a_{1} A}$ \\
\hline $0.7 \%$ LMP & $11.68 \pm 0.83^{\mathrm{a}, \mathrm{A}}$ & $11.28 \pm 0.78^{a_{1}} \mathrm{~A}$ & $10.92 \pm 0.80^{a_{1}} \mathrm{~A}$ & $10.24 \pm 0.78^{\mathrm{a}, \mathrm{A}}$ & $9.81 \pm 0.78^{\mathrm{a}_{1} \mathrm{~A}}$ \\
\hline $0.5 \%$ LMP & $11.47 \pm 0.64^{a, A}$ & $11.03 \pm 0.68^{\mathrm{a}_{1} \mathrm{~A}}$ & $10.37 \pm 0.62^{\mathrm{a}, \mathrm{A}}$ & $9.95 \pm 0.70^{\mathrm{a}, \mathrm{A}}$ & $9.55 \pm 0.82^{\mathrm{a}, \mathrm{A}}$ \\
\hline $0.3 \%$ LMP & $11.25 \pm 0.81^{a_{1}} \mathrm{~A}$ & $10.51 \pm 0.86^{a_{1}} \mathrm{~A}$ & $10.08 \pm 0.83^{a_{1}} \mathrm{~A}$ & $9.52 \pm 0.65^{\mathrm{a}, \mathrm{A}}$ & $9.31 \pm 0.73^{a_{1} A}$ \\
\hline Samples & \multicolumn{5}{|c|}{ polymeric color } \\
\hline $1.0 \%$ LMP & $1.18 \pm 0.09^{a, A}$ & $1.27 \pm 0.10^{\mathrm{a}, \mathrm{A}}$ & $1.46 \pm 0.12^{a_{1}} \mathrm{~A}$ & $1.79 \pm 0.15^{\mathrm{b}, \mathrm{A}}$ & $2.23 \pm 0.17^{c_{1} A}$ \\
\hline $0.7 \%$ LMP & $1.25 \pm 0.10^{\mathrm{a}, \mathrm{A}}$ & $1.36 \pm 0.12^{\mathrm{a}, \mathrm{A}}$ & $1.57 \pm 0.11^{\mathrm{a}, \mathrm{A}}$ & $2.14 \pm 0.16^{\mathrm{b}, \mathrm{A}}$ & $2.38 \pm 0.15^{c, A}$ \\
\hline $0.5 \%$ LMP & $1.37 \pm 0.11^{\mathrm{a}, \mathrm{A}}$ & $1.51 \pm 0.12^{\mathrm{a}, \mathrm{A}}$ & $1.73 \pm 0.14^{a_{1}} \mathrm{~A}$ & $2.37 \pm 0.16^{b, A B}$ & $2.71 \pm 0.18^{c_{1} A B}$ \\
\hline $0.3 \%$ LMP & $1.55 \pm 0.13^{\mathrm{a}, \mathrm{B}}$ & $1.73 \pm 0.14^{\mathrm{a}, \mathrm{B}}$ & $1.97 \pm 0.12^{\mathrm{a}, \mathrm{B}}$ & $2.71 \pm 0.20^{\mathrm{b}, \mathrm{B}}$ & $3.12 \pm 0.24^{c, B}$ \\
\hline Samples & \multicolumn{5}{|c|}{ percent polymeric color (\%) } \\
\hline $1.0 \%$ LMP & $9.98 \pm 0.65^{\mathrm{a}, \mathrm{A}}$ & $10.91 \pm 0.65^{\mathrm{a}, \mathrm{A}}$ & $13.02 \pm 0.71^{\mathrm{b}, \mathrm{A}}$ & $17.00 \pm 0.78^{c, A}$ & $22.14 \pm 1.21^{\mathrm{d}, \mathrm{A}}$ \\
\hline $0.7 \%$ LMP & $10.70 \pm 0.85^{\mathrm{a}, \mathrm{A}}$ & $12.07 \pm 0.72^{\mathrm{a}_{1} \mathrm{~A}}$ & $14.38 \pm 0.64^{\mathrm{b}, \mathrm{A}}$ & $20.90 \pm 1.15^{c, B}$ & $24.26 \pm 1.12^{\mathrm{d}, \mathrm{A}}$ \\
\hline $0.5 \%$ LMP & $11.94 \pm 0.87^{\mathrm{a}, \mathrm{A}}$ & $13.69 \pm 0.70^{\mathrm{a}, \mathrm{B}}$ & $16.68 \pm 0.78^{b, B}$ & $23.82 \pm 0.98^{c, C}$ & $28.38 \pm 1.33^{\mathrm{d}, \mathrm{B}}$ \\
\hline $0.3 \%$ LMP & $13.78 \pm 1.11^{\mathrm{a}, \mathrm{B}}$ & $16.46 \pm 0.86^{a_{1} c}$ & $19.54 \pm 0.93^{b, c}$ & $28.47 \pm 1.44^{c, D}$ & $33.51 \pm 1.77^{d, c}$ \\
\hline
\end{tabular}

Means in a row (a-d across storage time) followed by the same letter are not significantly different $(P<0.05)$. Means in a column (A-C across LMP concentration) followed by the same letter are not significantly different $(P<0.05)$. 
Table 4 Alterations of total phenolics content in jam as effect of LMP concentration and storage

\begin{tabular}{|c|c|c|c|c|c|}
\hline \multirow[t]{3}{*}{ Samples } & \multicolumn{5}{|c|}{ Total phenolics (mg gallic acid $100^{-1} \mathrm{~g}$ jam) } \\
\hline & \multicolumn{5}{|c|}{ storage time (months) } \\
\hline & 0 & 1 & 3 & 5 & 7 \\
\hline $1.0 \% \mathrm{LMP}$ & $275.41 \pm 18.73^{\mathrm{a}, \mathrm{A}}$ & $261.83 \pm 13.64^{a, A}$ & $244.80 \pm 18.74^{\mathrm{a}, \mathrm{A}}$ & $219.33 \pm 17.0^{\mathrm{ab}, \mathrm{A}}$ & $163.19 \pm 11.89^{\mathrm{b}, \mathrm{A}}$ \\
\hline $0.7 \%$ LMP & $260.11 \pm 17.0^{a_{1} \mathrm{~A}}$ & $239.71 \pm 15.33^{\mathrm{a}_{1,} \mathrm{~A}}$ & $219.32 \pm 15.30^{\mathrm{ab}, \mathrm{A}}$ & $193.78 \pm 15.35^{\mathrm{b}, \mathrm{A}}$ & $141.09 \pm 8.56^{\mathrm{C}, \mathrm{A}}$ \\
\hline $0.5 \%$ LMP & $248.22 \pm 13.61^{\mathrm{a}, \mathrm{A}}$ & $224.43 \pm 11.91^{a_{i} A}$ & $205.71 \pm 11.92^{\mathrm{ab}, A B}$ & $176.81 \pm 11.91^{\mathrm{b}, \mathrm{AB}}$ & $122.43 \pm 6.84^{c, A B}$ \\
\hline $0.3 \%$ LMP & $231.23 \pm 18.71^{\mathrm{a}, \mathrm{A}}$ & $204.03 \pm 17.3^{\mathrm{a}, \mathrm{AB}}$ & $181.93 \pm 13.61^{\mathrm{ab}, \mathrm{AB}}$ & $158.1 \pm 11.94^{\mathrm{b}, \mathrm{AB}}$ & $98.59 \pm 8.51$ c,AB \\
\hline
\end{tabular}

Means in a row (a-d across storage time) followed by the same letter are not significantly different $(\mathrm{P}<0.05)$. Means in a column (A-C across LMP concentration) followed by the same letter are not significantly different $(P<0.05)$.

storage period affects the TP content, but these changes showed statistical significance $(\mathrm{P}<0.05)$, only after 7 months of storage at $20^{\circ} \mathrm{C}$ (Table 4). Thus, after one month of storage at $20^{\circ} \mathrm{C}$, TP content decreased with 5$12 \%$ from the value recorded one day after processing. By extending the storage time to 7 months the losses reaching $41-47 \%$ from the value that was recorded after one day of processing (Figure 1b). At the end of the experiment, it was found that in the jams with higher LMP doses (0.7-1\%) the polyphenolic compounds are affected to a lesser extent than in the jams obtained with lower doses of pectin. This suggests that total phenolics compounds in bilberries jam with high LMP level have a better stability compared to jam with loss doses of pectin.

\section{L-ascorbic acid content}

Based on data registered for L-ascorbic acid content in fresh fruit (Table 1) and jam directly after processing (Table 5) and considering the amount of fresh fruit needed to obtain $100 \mathrm{~g}$, could be observed that thermal processing of fruit induced significant alterations in LAsAc content in agreement with other previous results [12]. Thus, thermal processing of fruit caused a loss of $53-58 \%$ from L-AsAc content recorded in fresh fruit. In Table 5 was showed the effect of LMP concentration and storage time at $20^{\circ} \mathrm{C}$ on L-AsAc content of bilberry jam.

By analyzing these data it can be noted that the decrease of LMP dose in the jam recipe causes a reduction in L-ascorbic acid content. The highest degree of
L-AsAc alteration was recorded in jam obtained with $0.3 \%$ pectin. By reducing of LMP level from 1 to $0.5 \%$ the recorded loss is around $4.5 \%$ from the L-ascorbic acid content and by lowering the LMP dose from 1 to $0.3 \%$ the losses were around $11 \%$. Storage at room temperature also influenced the amount of L-AsAc and the effect was more expressed in jam with $0.3 \%$ LMP than in jams with $0.7-1 \%$ LMP. It was found that a storage period of 3 months at $20^{\circ} \mathrm{C}$ induces loss of L-AsAc content of $14 \%$ for jam with $1 \%$ LMP and $22 \%$ for jam with 0.3\% LMP. However, statistical evaluation showed that 3 months of jam storage at room temperature there was no significance difference $(\mathrm{p}<0.05)$ in L-AsAc content regardless of the LMP concentration. Extending the storage period to 7 months resulted in significant alterations $(\mathrm{p}<0.05)$ in L-AsAc content, the losses reaching $41-53 \%$ from the value recorded one day after processing, (Figure 1c). During storage time, with decreasing of LMP concentration in the bilberry jam occurred significant loss of L-AsAc content. These observations suggest that L-AsAc was more stable in jam with high LMP doses in response of both processing and long-term storage at $20^{\circ} \mathrm{C}$.

\section{Antioxidant activity}

A comparison of the FRAP values in fresh fruit (Table 1) and jam (Table 6) showed that $36-47 \%$ of the corresponding fresh fruit antioxidant capacity was lost during jam processing. These results were consistent with data reported previously by Schmidt et al. [13], Savikin et al. [16], Scibisz et al. [17], Howard et al. [20], demonstrating

Table 5 Alterations of L-ascorbic acid content in jam as effect of LMP concentration and storage

\begin{tabular}{|c|c|c|c|c|c|}
\hline \multirow[t]{3}{*}{ Samples } & \multicolumn{5}{|c|}{ L-ascorbic acid (mg $100^{-1} \mathrm{~g}$ jam) } \\
\hline & \multicolumn{5}{|c|}{ storage time (months) } \\
\hline & 0 & 1 & 3 & 5 & 7 \\
\hline $1.0 \%$ LMP & $5.51 \pm 0.35^{\mathrm{a}, \mathrm{A}}$ & $5.08 \pm 0.22^{a, A}$ & $4.74 \pm 0.31^{a b, A}$ & $4.20 \pm 0.21^{b, A}$ & $3.27 \pm 0.24^{c, A}$ \\
\hline $0.7 \%$ LMP & $5.37 \pm 0.25^{\mathrm{a}, \mathrm{A}}$ & $4.91 \pm 0.30^{\mathrm{a}, \mathrm{A}}$ & $4.43 \pm 0.36^{a b, A}$ & $3.79 \pm 0.28^{\mathrm{b}, \mathrm{A}}$ & $2.85 \pm 0.18^{\mathrm{C}, \mathrm{A}}$ \\
\hline $0.5 \%$ LMP & $5.26 \pm 0.35^{\mathrm{a}, \mathrm{A}}$ & $4.74 \pm 0.26^{\mathrm{a}, \mathrm{A}}$ & $4.24 \pm 0.37^{\mathrm{ab}, \mathrm{A}}$ & $3.53 \pm 0.29^{b, A B}$ & $2.66 \pm 0.19^{\mathrm{C}, A B}$ \\
\hline $0.3 \%$ LMP & $4.91 \pm 0.37^{\mathrm{a}, \mathrm{A}}$ & $4.32 \pm 0.30^{\mathrm{a}, \mathrm{A}}$ & $3.85 \pm 0.35^{\mathrm{ab}, \mathrm{A}}$ & $3.15 \pm 0.21^{\mathrm{b}, \mathrm{AB}}$ & $2.30 \pm 0.15^{c_{1} A B}$ \\
\hline
\end{tabular}

Means in a row (a-d across storage time) followed by the same letter are not significantly different $(P<0.05)$. Means in a column (A-C across LMP concentration) followed by the same letter are not significantly different $(P<0.05)$. 
Table 6 Alterations of antioxidant activity in jam as effect of LMP concentration and storage

\begin{tabular}{|c|c|c|c|c|c|}
\hline \multirow[t]{3}{*}{ Samples } & \multicolumn{5}{|c|}{ Antioxidant activity (mM Fe ${ }^{2+\cdot} 100^{-1}$ jam) } \\
\hline & \multicolumn{5}{|c|}{ storage time (months) } \\
\hline & 0 & 1 & 3 & 5 & 7 \\
\hline $1.0 \%$ LMP & $2.45 \pm 0.18^{\mathrm{a}, \mathrm{A}}$ & $2.30 \pm 0.14^{\mathrm{a}, \mathrm{A}}$ & $2.18 \pm 0.16^{\mathrm{a}, \mathrm{A}}$ & $1.99 \pm 0.13^{\mathrm{ab}, \mathrm{A}}$ & $1.64 \pm 0.12^{\mathrm{b}, \mathrm{A}}$ \\
\hline $0.7 \%$ LMP & $2.35 \pm 0.17^{\mathrm{a}, \mathrm{A}}$ & $2.18 \pm 0.16^{\mathrm{a}, \mathrm{A}}$ & $2.03 \pm 0.15^{\mathrm{a}, \mathrm{A}}$ & $1.82 \pm 0.09^{\mathrm{ab}, \mathrm{A}}$ & $1.46 \pm 0.09^{\mathrm{b}, \mathrm{A}}$ \\
\hline $0.5 \%$ LMP & $2.14 \pm 0.17^{a_{1} A}$ & $1.97 \pm 0.14^{a_{1}} \mathrm{~A}$ & $1.80 \pm 0.13^{\mathrm{a}, \mathrm{A}}$ & $1.59 \pm 0.15^{\mathrm{ab}, \mathrm{AB}}$ & $1.27 \pm 0.09^{b}, A B$ \\
\hline $0.3 \%$ LMP & $2.02 \pm 0.14^{\mathrm{a}, \mathrm{A}}$ & $1.80 \pm 0.12^{\mathrm{a}, \mathrm{Ab}}$ & $1.62 \pm 0.15^{\mathrm{ab}, A B}$ & $1.47 \pm 0.09^{b, B}$ & $1.08 \pm 0.10^{c_{1} B}$ \\
\hline
\end{tabular}

Means in a row (a-d across storage time) followed by the same letter are not significantly different $(P<0.05)$. Means in a column $(A-C$ across $L M P$ concentration) followed by the same letter are not significantly different $(P<0.05)$.

that the antioxidant capacity of different berries significantly decreased after jam processing. This decrease can be attributed to the destruction of anthocyanins, phenolics compounds as well as L-ascorbic acid as a result of thermal treatment. Despite significant losses of anthocyanins during thermal processing of fruit, the FRAP values recorded for jam were affected to a lesser extent. It was observed that thermal treatment has a lower impact on FRAP recorded in jam with high concentration of pectin. By decreasing the LMP dose in the bilberry jam formulation, antioxidant capacity declined (Table 6). Thus, by decreasing of the LMP dose from 1 to $0.3 \%$ there is a loss of antioxidant capacity of $17.53 \%$ of the values recorded one day after processing. In terms of changes in antioxidant capacity in response to storage, it is found that increases of storage time resulted in depreciations of antioxidant activity in the bilberry jam, depending on LMP concentration. The losses recorded in antioxidant activity after 3 month of storage at $20^{\circ} \mathrm{C}$ were in the range $11-20 \%$ relative to the value recorded one day after processing and after 7 months reached 33-46\% from the value recorded one day after processing (Figure 1d). However, after 3 months of storage at $20^{\circ} \mathrm{C}$ there was no statistical significant difference $(\mathrm{p}<0.05)$ in the antioxidant activity of investigated jams. Only after 7 months of storage, the alterations of FRAP were statistically significant $(\mathrm{p}<0.05)$ for all LMP levels. We can say that the depreciation of the antioxidant properties of bilberry jam is accentuated by decreasing of pectin dose in the jam formulation as well as prolonged of storage time at $20^{\circ} \mathrm{C}$. In respect of the storage effect, the alterations of FRAP values of jam was significant ( $\mathrm{p}<0.05)$, depending on the pectin concentration.

\section{Correlations}

A high positive correlation was detected between FRAP values and TP content recorded during the storage period $(r>0.99)$ (Table 7). FRAP was also highly correlated with TMA content $(r>0.98)$ and with L-AsAc content $(\mathrm{r}>0.99)$. A positive correlation between TP and TMA ( $r>0.97$ ) was observed, which is logical because anthocyanins are the most important phenolic compounds present in bilberry $[4,5]$.
Prior et al. [6] noted that phytochemicals responsible for the antioxidant activity in berries are most likely to be phenolic acids, anthocyanins, and other flavonoid compounds. A significant negative correlation was found between TMA content and polymeric color percent $(\mathrm{r}>$ 0.97 ) indicating that more polymeric products were accumulated with total anthocyanin degradation. Also, our results indicate that FRAP values and \% polymeric color were negatively correlated $(r>0.96)$. In fruits such as bilberries and in correspondent jam, where phenolic components and, more specifically, anthocyanins, make a significant contribution to total antioxidant activity, simple colorimetric tests such as the Folin-Ciocalteu test [37] for phenolics or the Giusti and Wrolstad anthocyanin test [38] can be useful in estimating changes in antioxidant activity during storage. Although total phenolics and L-ascorbic acid are the major potential candidates as a selection criterion for antioxidant properties of berries jams, antioxidant activity is not limited to these [12,26,27]. Previous results obtained by Tsai et al. [39], Brownmiller et al. [25] proved that polymeric anthocyanins show antioxidant activity, which compensates for the loss of a part of antioxidant activity due to monomeric anthocyanins degradation. Also, it has been proven that some degradation products of anthocyanins have the antioxidant activity [40]. Our data suggest that, after 7 months of storage at $20^{\circ} \mathrm{C}$, antioxidant activity of fruit jam recorded lower depreciation compared with the content of investigated bioactive compounds. This is confirmed by the fact that a

Table 7 Correlation coefficients obtained by simple regression model applied for investigated parameters

\begin{tabular}{|c|c|c|c|c|}
\hline \multirow[t]{2}{*}{$Y=A+B \cdot X$} & \multicolumn{4}{|c|}{ correlation coefficient $(r)$} \\
\hline & $\begin{array}{l}1 \% \\
\text { LMP }\end{array}$ & $\begin{array}{l}0.7 \% \\
\text { LMP }\end{array}$ & $\begin{array}{l}0.5 \% \\
\text { LMP }\end{array}$ & $\begin{array}{l}0.3 \% \\
\text { LMP }\end{array}$ \\
\hline$F R A P=f(T P)$ & 0.99612 & 0.99915 & 0.99905 & 0.99815 \\
\hline$F R A P=f(T M A)$ & 0.98922 & 0.99379 & 0.99546 & 0.99451 \\
\hline$F R A P=f(L-A s A C)$ & 0.99983 & 0.99926 & 0.99937 & 0.99399 \\
\hline$T P=f(T M A)$ & 0.97696 & 0.98871 & 0.99675 & 0.98994 \\
\hline $\begin{aligned} \text { TMA }= & f(\% \text { polymeric } \\
& \text { color })\end{aligned}$ & -0.9851 & $-0,97314$ & $-0,97411$ & $-0,9739$ \\
\hline $\begin{aligned} \text { FRAP }= & f(\% \text { polymeric } \\
& \text { color })\end{aligned}$ & $-0,99237$ & $-0,97592$ & $-0,98511$ & $-0,96569$ \\
\hline
\end{tabular}


storage period of 7 months does not induce significant changes in FRAP values, while for the other measured parameters such as total phenolics, monomeric anthocyanins, L-ascorbic acid were noticed significant changes. More studies are required for comprehensive assessment of polymeric anthocyanins contribution to antioxidant activity of bilberry jam in storage.

\section{Conclusions}

It could be concluded from the results of this study that thermal processing of wild bilberries into low-sugar jams resulted in significant losses in TMA, TP, L-AsAc content and FRAP values. They also suggest that, TMA are more susceptible than the TP during thermal processing of bilberry. LMP concentration and storage time affected the antioxidant properties as well as color characteristics of bilberry jams. Thus, by increasing of LMP dose in jam recipe from 0.3 to $1 \%$ there was an increase in bioactive compounds and FRAP values. In terms of color quality, polymeric color was higher when jams were produced with low pectin concentration. For the same dose of pectin, with increasing of storage period was recorded an increase in depreciation of antioxidant characteristics. The storage of bilberry jam at $20^{\circ} \mathrm{C}$ for 1-3 months determined mild or moderate alterations of investigates parameters, while 7 months of storage induced statistically significant alterations. The losses of monomeric anthocyanins during storage of processed bilberry jams were accompanied by increased in the polymeric color values, indicating that monomeric anthocyanins were extensively polymerized. The polymeric color values gradually increased during jam storage, the largest increases occurring at the end of experiment, after 7 months. Despite significant losses of total monomeric anthocyanins, the color density values changed little during jam storage at $20^{\circ} \mathrm{C}$, suggesting that polymeric compounds formed compensated the loss of color due to degradation of monomeric anthocyanins, proving the stability of the jam color during 7 months of storage. Taking into account all these factors, and in spite of the fact that some losses occur in the content of total phenolics, anthocyanins, L-ascorbic acid as well as antioxidant activity, low-sugar bilberry jams are still excellent sources of nutritional substances with antioxidant potential. These products offer an important opportunity to create a healthy, seasonally independent and mixed diet.

\section{Experimental}

Berries

Bilberries (Vaccinium myrtillus L.) have been harvested in the summer of 2009 at the fully ripe stage from their natural habitat (mountain region of western Romania, altitude $1200-1400 \mathrm{~m}$ ). The berries were stored at $4^{\circ} \mathrm{C}$ for one day prior to processing.

\section{Jam processing}

Low-sugar bilberry jams were prepared in the laboratory, according to a traditional procedure, by boiling in an open kettle under atmospheric pressure, with manual stirring. The final soluble solids content reached upon cooking was $45^{\circ}$ Brix. For the jams preparation, fruit $(900 \mathrm{~g}$ ) was blended and then cooked under atmospheric pressure with the addition of sucrose ( $470 \mathrm{~g}$ ) Commercial low-methoxyl pectin (LM40, Danisco Ingredients, Denmark) was added at four different concentrations, $0.3,0.5,0.7$ and $1 \%(\mathrm{~m} / \mathrm{V})$ at the final stage of the jam cooking. Citric acid was added towards the end of cooking for adjusting $\mathrm{pH}$ values for proper LMP gelatinization (2.8-3.3). Time of thermal processing was $\sim 30 \mathrm{~min}$ at $80^{\circ} \mathrm{C}$ until the final product reached $45^{\circ}$ Brix (determined with an Abbe refractometer at $20^{\circ} \mathrm{C}$ ). The jam were filled into hot glass jars, capped and pasteurized at $80^{\circ} \mathrm{C}$ for $10 \mathrm{~min}$. They were allowed to cool at room temperature and stored in the dark until analysis. Jams were analyzed after a day of processing $(0)$ and after 1, 3, 5 and 7 months of storage at $20^{\circ} \mathrm{C}$.

By measure the weight of the jams before and after processing it was obtained the water loss incurred during cooking (aproximately $45 \mathrm{~g}$ per $1 \mathrm{~kg}$ of bilberry jam). Considering water loss recorded during thermal treatment, fresh fruit content per $100 \mathrm{~g}$ jam was recalculated (about $69 \mathrm{~g}$ per $100 \mathrm{~g}$ jam). The amount of fruit needed to obtain $100 \mathrm{~g}$ jam provides information about the theoretical content of bioactive compounds from the bilberry jam. The difference between the theoretical content of investigated parameters and the real content recorded for bilberry jam was caused by thermal processing.

\section{Analytical procedures Chemicals}

2,4,6-tripyridyl-s-triazine (TPTZ), gallic acid, Folin\&Ciocalteu's phenol reagent, sodium acetate, $\mathrm{FeCl}_{3} \cdot \mathrm{H}_{2} \mathrm{O}$, ACS spectrophotometric grade ethanol and other unspecified reagents were purchased from Sigma-Aldrich (Germany).

\section{Preparation of extracts}

In order to determine the total monomeric anthocyanins content, color density, polymeric color, total phenolic content, L-ascorbic acid and antioxidant activity, three replicates of fresh fruit and jam extracts were prepared according to Kalt et al. [41].

The extracts for monomeric anthocyanins content and color evaluation were obtained by blended samples $(\sim 5 \mathrm{~g})$ in $95 \%(\mathrm{v} / \mathrm{v})$ ethanol $(20 \mathrm{~mL})$ acidified with $\mathrm{HCl}(0.1 \%, \mathrm{v} / \mathrm{v})$ for $2 \mathrm{~min}$. The mixture was stored at room temperature in the dark for $24 \mathrm{~h}$ and then filtered. 
The extracts for analysis of total phenolics and Lascorbic acid were obtained by blended samples $(\sim 5 \mathrm{~g})$ in hot $95 \%(\mathrm{v} / \mathrm{v})$ ethanol $(10 \mathrm{~mL})$ for $2 \mathrm{~min}$. The solution was filtered. The extraction of the residue was repeated twice following above mentioned procedure. Three extracts were combined.

The extracts for antioxidant activity determination were obtained by blended samples ( 20 g) in $95 \%(\mathrm{v} / \mathrm{v})$ ethanol $(20 \mathrm{~mL})$ acidified with $\mathrm{HCl}(0.1 \%)$. After $60 \mathrm{~min}$ the solution was filtered. The residue was extracted again. The extracts were combined and diluted to volume of $50 \mathrm{~mL}$ with ethanol acidified with $\mathrm{HCl}(0.1 \%)$.

\section{Total phenolic assay}

The total phenolic content was quantified according to the method of Singleton et al. [37]. Briefly, an aliquot of $12.5 \mu \mathrm{l}$ of extract was mixed with $250 \mu \mathrm{l}$ of $2 \%$ sodium carbonate solution and allowed to react for 5 minutes at room temperature. Then $12.5 \mu \mathrm{l}$ of Folin-Ciocalteu phenol reagent (50\%) was added and allowed to stand for 30 minutes at room temperature before the absorbance of the reaction mixture was read at $750 \mathrm{~nm}$ using the UV-VIS spectrophotometer (Analytic Jena Specord 205). Calibration was achieved with a gallic acid solution (10$\left.100 \mathrm{mg} \cdot \mathrm{L}^{-1}\right)$. Results were expressed as $\mathrm{mg}$ gallic acid equivalent (GAE) per $100 \mathrm{~g}$ fresh bilberries, respectively jam (when calculating results of TP for bilberries jam). All determinations were performed in triplicate.

\section{Antioxidant activity (FRAP assay)}

The antioxidant activity of fresh berries, as well as of related jams was measured using the ferric reducing antioxidant power (FRAP) assay, a colorimetric test that measures the ability of the tested sample to reduce the ferric 2,4,6-tris(2-pyridyl)-1,3,5-triazine (TPTZ) complex to a blue-colored ferrous form at $37^{\circ} \mathrm{C}$ in $\mathrm{pH} 3.6$ sodium acetate buffer, thereby changing its absorbance [42,43]. An aliquot of $8.5 \mu \mathrm{l}$ of extract was added to $275 \mu \mathrm{l}$ of diluted FRAP reagent and the samples were incubated at $37^{\circ} \mathrm{C}$ for 30 minutes before measuring the absorbance at $595 \mathrm{~nm}$. A standard curve was prepared using different concentrations $\left(0.05-0.4 \mathrm{mM} \mathrm{Fe} \mathrm{Fe}^{2+\cdot} \mathrm{L}^{-1}\right)$ of FeS$\mathrm{O}_{4} \cdot 7 \mathrm{H}_{2} \mathrm{O}$. The antioxidant activity based on the ability to reduce ferric ions of the extract was expressed as $\mathrm{mM} \mathrm{Fe}^{2+}$ equivalents per $100 \mathrm{~g}$ fresh bilberries, respectively jam. All solutions were used on the day of preparation and all determinations were performed in triplicate.

\section{Determination of L-Ascorbic acid}

L-Ascorbic acid or vitamin C content was measured by titration with a 2,6-dichlorophenolindophenol sodium salt solution and chloroform was used for intensely colored extracts (AOAC) [44]. Results were expressed in mg L-AsAc equivalent per $100 \mathrm{~g}$ fresh bilberries, respectively jam.
Total monomeric anthocyanin content, color density and polymeric color measurements

Total monomeric anthocyanin content was performed using a $\mathrm{pH}$ differential method [38]. Anthocyanin pigments undergo reversible structural transformations with a change in $\mathrm{pH}$ manifested by different absorbance spectra. The colored oxonium form predominates at $\mathrm{pH}$ 1.0 and the colorless hemiketal form at $\mathrm{pH} 4.5$. An aliquot of an appropriately diluted extracts was adjusted to $\mathrm{pH} 1.0$ and another aliquot to $\mathrm{pH}$ 4.5. The difference in absorbance at $520 \mathrm{~nm}$ is proportional to the TMA content. Sample extracts were further diluted 15-fold with $0.025 \mathrm{M}$ potassium chloride buffer $(\mathrm{pH}=1.0)$ or $0.4 \mathrm{M}$ sodium acetate buffer $(\mathrm{pH}=4.5)$. The absorbance of each dilution was measured at 520 and $700 \mathrm{~nm}$ against a distilled water blank using a UV-visible spectrophotometer (Specord 205 by Analytik Jena) and $1 \mathrm{~cm}$ path length glass cells.

The absorbance value (A) calculated according to the equation (1) is proportional to the total monomeric anthocyanin content.

$$
A=\left(A_{520 n m}-A_{700 n m}\right)_{p H=1.0}-\left(A_{520 n m}-A_{700 n m}\right)_{p H=4.5}
$$

The monomeric anthocyanins content was expressed as mg per $100 \mathrm{~g}$ fresh bilberries, respectively jam using a molar extinction coefficient of 26900 and a molecular weight of 449.2 of the most prevalent anthocyanin (usually cyanidin-3-glucoside). All measurements were done in triplicate.

The percent contribution by polymerized anthocyanins was evaluated using absorbance values at the specified wavelengths, determined with and without added potassium metabisulfite [38]. All of the measurements were done in triplicate. Sample extracts were diluted with water in order to have an absorbance reading between 0.5 and 1.0 at $520 \mathrm{~nm}$. For analysis, $0.2 \mathrm{~mL}$ of $0.90 \mathrm{M}$ potassium metabisulfite were added to $2.8 \mathrm{~mL}$ diluted sample (bisulfite bleached sample) and $0.2 \mathrm{~mL}$ of distilled water were added to $2.8 \mathrm{~mL}$ diluted sample (non bleached, control sample). After equilibrating for 15 min samples were evaluated at $\lambda=700,520$, and $420 \mathrm{~nm}$.

Color density was calculated using the control sample according to the equation (2):

$$
\text { Color dencity }=\left[\left(\mathrm{A}_{420 \mathrm{~nm}}-\mathrm{A}_{700 \mathrm{~nm}}\right)+\left(\mathrm{A}_{520 \mathrm{~nm}}-\mathrm{A}_{700 \mathrm{~nm}}\right)\right] \cdot \text { dilution factor }
$$

Polymeric color was determined using the bisulfitebleached sample using the equation (3):

Polymeric color $=\left[\left(\mathrm{A}_{420 \mathrm{~nm}}-\mathrm{A}_{700 \mathrm{~nm}}\right)+\left(\mathrm{A}_{520 \mathrm{~nm}}-\mathrm{A}_{700 \mathrm{~nm}}\right)\right] \cdot$ dilution factor 
Percent polymeric color was calculated using the equation (4):

$$
\text { Polymeric color }(\%)=\frac{\text { polymeric color }}{\text { color density }} \cdot 100
$$

\section{Statistical analysis}

Results are presented as means \pm standard deviation (SD) of triplicate measurements. Significant statistical differences of investigated parameters were determined by Fisher's least significant differences (LSD) test at $\mathrm{P}<$ 0.05 , after analysis of variance (ANOVA) of a two-factor experiment in an factorial designs with four LMP concentration, five storage period and three replicates as sources of variation. Computations Tukey post-hoc means comparisons and Levene's test for equal variance was also included. Statistical processing of data was performed using the statistical program known as the Statistical Analysis System (SAS, 2001). Correlations between investigated parameters were established by regression analysis.

\section{Abbreviations}

LMP: low-methoxyl pectin; TMA: total monomeric anthocyanins; TP: total phenolics; L-AsAc: L-ascorbic acid; FRAP: ferric reducing antioxidant power.

\section{Acknowledgements}

This study was supported by S.C. ETCO EUROPE TRADE COMPANY from SEBIS (ARAD), research project no. 637/21.01.2009, Theme: Studies regarding the impact of technological treatments on the antioxidant characteristics of products from berries, Project Manager: Ph.D Assoc. Prof. Mariana-Atena Poiana

\section{Authors' contributions}

MAP conceived the research design, performed jam processing, TMA, FRAP and color analysis, results interpretation and manuscript preparation. EA contributed to jam processing, performed extractions, TP and L-AsAc analysis, CM contributed to the color analysis, performed statistical analyses and helped to interpretation of data. All authors read and approved the final version of the manuscript

\section{Competing interests}

The authors declare that they have no competing interests.

Received: 10 November 2011 Accepted: 16 January 2012 Published: 16 January 2012

\section{References}

1. Giovanelli G, Buratti S: Comparison of polyphenolic composition and antioxidant activity of wild Italian blueberries and some cultivated varieties. Food Chem 2009, 112:903-908.

2. Jabłonska-Rys E, Zalewska-Korona M, Kalbarczyk J: Antioxidant capacity, ascorbic acid and phenolics content in wild edible fruits. J Fruit Ornam Plant Res 2009, 17:115-120.

3. Rababah TM, Al-Mahasneh MA, Kilani I, Yang W, Alhamad MN, Ereifej K, AlU'datt M: Effect of jam processing and storage on total phenolics, antioxidant activity, and anthocyanins of different fruits. J Sci Food Agric 2011, 91:1096-1102.

4. Skrede G, Wrolstad RE, Durst RW: Changes in anthocyanins and polyphenolics during juice processing of highbush blueberries (Vaccinium corymbosum L.). J Food Sci 2000, , 65: 357-364.
5. Moyer RA, Hummer KE, Finn CE, Frei B, Wrolstad RE: Anthocyanins, phenolics, and antioxidant capacity in diverse small fruits: Vaccinium, Rubus and Ribes. J Agric Food Chem 2002, 50:519-25.

6. Prior RL, Cao G, Martin A, Sofic E, McEwen J, O'Brien C, Lischner N, Ehlenfeldt M, Kalt W, Krewer G, Mainland CM: Antioxidant capacity as influenced by total phenolic and anthocyanin content, maturity, and variety of Vaccinium species. J Agr Food Chem 1998, 46:2686-2693.

7. Proteggente AR, Pannala AS, Paganga $G$, Van Buren $L$, Wagner $E$, Wiseman S, Van De Put F, Dacombe C, Rice-Evans CA: The antioxidant activity of regularly consumed fruit and vegetables reflects their phenolic and vitamin C composition. Free Radic Res 2002, 36:217-233.

8. Kalt W, Mc Donald JE, Donnor H: Anthocyanins, phenolics, and antioxidant capacity of processed lowbush blueberry products. J Food Sci 2000, 65:390-393.

9. Smith MAL, Marley KA, Seigler D, Singletary KW, Meline B: Bioactive properties of wild blueberry fruits. J Food Sci 2000, 65:352-356.

10. Zafra-Stone S, Yasmin T, Bagchi M, Chatterjee A, Vinson JA, Bagchi D: Berry anthocyanins as novel antioxidants in human health and disease prevention. Mol Nutr Food Res 2007, 51:675-683.

11. Rossi M, Giussani E, Morelli R, Lo Scalzo R, Nani RC, Torreggiani D: Effect of fruit blanching on phenolics and radical scavenging activity of highbush blueberry juice. Food Res Int 2003, 36:999-1005.

12. Klopotek Y, Otto K, Bohm V: Processing strawberries to different products alters contents of vitamin $C$, total phenolics, total anthocyanins, and antioxidant capacity. J Agric Food Chem 2005, 53:5640-5646.

13. Schmidt BM, Erdman JW Jr, Lila MA: Effects of food processing on blueberry antiproliferation and antioxidant activity. J Food Sci 2005, 70: S389-394.

14. Szajdek A, Borowska EJ: Bioactive compounds and health-promoting properties of berry fruits: A review. Plant Food Hum Nutr 2008, 63:147-156.

15. Gimenez J, Kajda P, Margomenou L, Piggott JR, Zabetakis I: A study on the colour and sensory attributes of high-hydrostatic-pressure jams as compared with traditional jams. J Sci Food Agric 2001, 81:1228-1234.

16. Savikin K, Zdunic G, Jankovic T, Tasic S, Menkovic N, Stevic T, Dordevic B: Phenolic content and radical scavenging capacity of berries and related jams from certificated area in Serbia. Plant Foods Hum Nutr 2009, 64:212-217.

17. Scibisz I, Mitek M: Effect of processing and storage conditions on phenolic compounds and antioxidant capacity of highbush blueberry jams. Pol J Food Nutr Sci 2009, 59:45-52.

18. Yuksel S, Koka I: Color stability of blackberry nectars during storage. $J$ Food Technol 2008, 6:166-169

19. Wrolstad RE, Durst RW, Lee J: Tracking color and pigment changes in anthocyanin products. Trends Food Sci Tech 2005, 16:423-428.

20. Howard LR, Castrodale C, Brownmiller C, Mauromoustakos A: Jam processing and storage effects on blueberry polyphenolics and antioxidant capacity. J Agric Food Chem 2010, 58:4022-4029.

21. Garcia-Viguera C, Zafrilla P, Artes F, Romero F, Abellan P, TomasBarberan FA: Colour and anthocyanin stability of red raspberry jam. J Sci Food Agric 1998, 78:565-573.

22. Garcia-Viguera C, Zafrilla P, Romero F, Abellan P, Artes F, TomasBarberan FA: Color stability of strawberry jam as affected by cultivar and storage temperature. J Food Sci 1999, 64:243-247.

23. Kim DO, Padilla-Zakour Ol: Jam processing effect on phenolics and antioxidant capacity in anthocyanin-rich fruits: cherry, plum and raspberry. J Food Sci 2004, ,69: 395-400.

24. Srivastava A, Akoh CC, Yi W, Fischer J, Krewer G: Effect of storage conditions on the biological activity of phenolic compounds of blueberry extract packed in glass bottles. J Agric Food Chem 2007, 55:2705-2713.

25. Brownmiller C, Howard LR, Prior RL: Processing and storage effects on monomeric anthocyanins, percent polymeric color, and antioxidant capacity of processed blueberry products. J Food Sci 2008, 73:H72-79.

26. Ngo T, Wrolstad RE, Zhao Y: Color quality of Oregon strawberries - impact of genotype, composition and processing. J Food Sci 2007, 72:C25-32.

27. Bursac Kovacevic D, Levaj B, Dragovic-Uzelac V: Free radical scavenging activity and phenolic content in strawberry fruit and jam. Agriculturae Conspectus Scientificus 2009, 74:155-159.

28. Maier T, Fromm M, Schieber A, Kammerer DR, Carle R: Process and storage stability of anthocyanins and non-anthocyanin phenolics in pectin and 
gelatin gels enriched with grape pomace extracts. Eur Food Res Technol 2009, 229:949-960

29. Kopjar M, Pilizota V, Tiban NN, Subaric D, Babic J, Ackar D: Effect of different pectin addition and its concentration on colour and textural properties of raspberry jam. Deutsch Lebensm Runds 2007, 103:164-168.

30. Kopjar M, Pilizota V, Tiban NN, Subaric D, Babic J, Ackar D, Sajdl M: Strawberry jams: influence of different pectins on colour and textural properties. Czech J Food Sci 2009, 27:20-28.

31. Pinto MS, Lajolo FM, Genovese MI: Bioactive compounds and antioxidant capacity of strawberry jams. Plant Foods Hum Nutr 2007, 62:127-131.

32. Lewis CE, Walker JRL, Lancaster JE: Effect of polysaccharides on the colour of anthocyanins. Food Chem 1995, 54:315-319.

33. Kopjar M, Pilizota V, Subaric D, Babic J: Prevention of thermal degradation of red currant juice anthocyanins by phenolic compounds addition. Croat J Food Sci Technol 2009, 1: 24-30.

34. Withy LM, Nguyen TT, Wrolstad RE, Heatherbell DA: Storage changes in anthocyanin content of red raspberry juice concentrate. J Food Sci 1993, 58:190-192.

35. Hubbermann EM, Heins A, Stőckmann H, Schwarz K: Influence of acids, salt, sugars and hydrocolloids on the colour stability of anthocyanins rich blackcurrant and elderberry concentrates. Eur Food Res Tech 2006, 223:83-90.

36. Rommel A, Wrolstad RE, Heatherbell DA: Blackberry juice and wine: processing and storage effects on anthocyanin composition, color and appearance. J Food Sci 1992, 57:385-391.

37. Singleton VL, Orthofer R, Lamuela-Raventos RM: Analysis of total phenols and other oxidation substrates and antioxidants by means of FolinCiocalteu reagent. Meth Enzymol 1999, 299:152-178.

38. Giusti MM, Wrolstad RE, Unit F1.2: Characterization and measurement of anthocyanins by UV-visible spectroscopy. In Handbook of food analytical chemistry-pigments, colorants, flavors, texture, and bioactive food components. Edited by: Wrolstad RE. New York: Wiley and Sons; 2005:1-13.

39. Tsai PJ, Huang HP, Huang TC: Relationship between anthocyanin patterns and antioxidant capacity in mulberry wine during storage. J Food Quality 2004, 27:497-505.

40. Tsai O, Huang H: Effect of polymerization on the antioxidant capacity of anthocyanins in Roselle. Food Res Int/ 2004, 37:313-318.

41. Kalt W, Forney CF, Martin A, Prior RL: Antioxidant capacity, vitamin C, phenolics and anthocyanins after fresh storage of small fruits. J Agric Food Chem 1999, 47:4638-4644.

42. Benzie IFF, Strain L: Ferric reducing ability of plasma (FRAP) as a measure of antioxidant power: The FRAP assay. Anal Biochem 1996, 239:70-76.

43. Stef DS, Gergen I, Trasca TI, Harmanescu M, Stef L, Biron R, Hegedus MG Total antioxidant and radical scavenging capacities for different medicinal herbs. Rom Biotech Lett 2009, 14:4705-4710.

44. AOAC: Vitamin C (ascorbic acid) in vitamin preparations and juices. In Official Methods of Analysis.. 15 edition. Edited by: Helrich K. AOAC, Inc., Arlington VA; 2000:1058.

doi:10.1186/1752-153X-6-4

Cite this article as: Poiana et al:: Tracking antioxidant properties and color changes in low-sugar bilberry jam as effect of processing, storage and pectin concentration. Chemistry Central Journal 2012 6:4.

Publish with ChemistryCentral and every
scientist can read your work free of charge
"Open access provides opportunities to our
colleagues in other parts of the globe, by allowing
anyone to view the content free of charge."
W. Jeffery Hurst, The Hershey Company.
- available free of charge to the entire scientific community
- peer reviewed and published immediately upon acceptance
- cited in PubMed and archived on PubMed Central
- yours - you keep the copyright
Submit your manuscript here:
http://www.chemistrycentral.com/manuscript/

